\title{
PARALYSIS AGITANS MORTALITY IN ENGLAND AND WALES, 1855-1962*
}

\author{
BY \\ ROGER C. DUVOISIN AND MORTON D. SCHWEITZER \\ From the Department of Neurology, College of Physicians and Surgeons, and the Division of Epidemiology. \\ School of Public Health and Administrative Medicine, Columbia University, N.Y.
}

The causes of death in England and Wales have been published in tabular form in the annual reports of the Registrar General since 1837 when Dr William Farr first applied statistical methods to the analysis of the English death roll. The classification of causes of death which Farr developed for this purpose (General Register Office, 1845) included the "shaking palsy", and deaths ascribed to this entity tabulated according to age and sex may be found in the annual reports for the years 1855 to 1880 inclusive. Farr's successor, William Ogle, introduced in 1881 an improved classification based on the new nomenclature of disease of the Royal College of Physicians of London (Idem, 1881). In the new nosology specific medical terms largely replaced the common or popular names previously employed; "paralysis agitans" thus superseded the "shaking palsy". The Registrar General continued to publish the number of deaths assigned each year to this cause up to the year 1900 . One notes with interest that Charcot (1880) and Sanders (1879) made reference to these reports in their clinical writings.

As an unfortunate by-product of changes in the recording of mortality statistics coincident with the introduction of the first international statistical classification in 1901, the mortality ascribed to paralysis agitans was no longer tabulated separately. Publication of data for this disease was resumed in 1921 when the third revision of the International List was adopted. There is thus available, except for the 20-year gap 1901-20, a continuous record of mortality due to paralysis agitans in England and Wales from 1855 to the present representing the most extensive available mortality data on this disease.

* Supported by NINDB Grant No. NB-05184-02 and Contract PH 436454.
It seems curious in view of the widespread interest in the epidemiology of Parkinson's disease in recent years that so remarkable a store of information has not been systematically examined. The present communication seeks to remedy this oversight and to present a brief review and analysis of this material.

\section{5-80}

Despite the archaic nature of Farr's nosology, and the limitations in the vital statistics of that period, it is interesting to examine the oldest epidemiological data on paralysis agitans. The frequency and distribution of mortality from this cause between 1855 and 1962 is summarized in Table I. A total of 1,472 deaths were assigned to the shaking palsy in the years 1855 to 1880 . Approximately 95 per cent. occurred in individuals above 55 years of age, and males outnumbered females in the ratio $3: 2$. The rapid increase in the number of deaths assigned each

TABLE I

PARALYSIS AGITANS MORTALITY IN ENGLAND AND WALES, 1855-1962, BY AGE

\begin{tabular}{|c|c|c|c|c|c|c|}
\hline \multirow{2}{*}{ Period } & \multirow{2}{*}{$\begin{array}{c}\text { No. of } \\
\text { Deaths } \\
\text { per } \\
\text { Year }\end{array}$} & \multicolumn{5}{|c|}{ Age (yrs) } \\
\hline & & $\underset{45}{\text { Under }}$ & $45-54$ & $55-64$ & $65-74$ & $75+$ \\
\hline $\begin{array}{l}1855-60 \\
1861-70 \\
1871-80\end{array}$ & $\begin{array}{l}21 \\
38 \\
97\end{array}$ & $\begin{array}{l}* \\
2 \\
3\end{array}$ & $\begin{array}{l}1 \\
3 \\
4\end{array}$ & $\begin{array}{r}5 \\
8 \\
19\end{array}$ & $\begin{array}{l}10 \\
15 \\
41\end{array}$ & $\begin{array}{r}5 \\
10 \\
30\end{array}$ \\
\hline $\begin{array}{l}1881-90 \\
1891-1900\end{array}$ & $\begin{array}{l}190 \\
303\end{array}$ & $\begin{array}{l}2 \\
3\end{array}$ & $\begin{array}{r}9 \\
11\end{array}$ & $\begin{array}{l}37 \\
54\end{array}$ & $\begin{array}{r}84 \\
143\end{array}$ & $\begin{array}{l}58 \\
92\end{array}$ \\
\hline $\begin{array}{l}1921-25 \\
1926-30 \\
1931-35 \\
1936-40 \\
1941-45 \\
1946-50 \\
1951-55 \\
1956-60 \\
1961-62\end{array}$ & $\begin{array}{r}800 \\
1,128 \\
1,404 \\
1,455 \\
1,204 \\
1,335 \\
1,546 \\
1,592 \\
1,667\end{array}$ & $\begin{array}{r}11 \\
13 \\
13 \\
16 \\
19 \\
17 \\
14 \\
10 \\
6\end{array}$ & $\begin{array}{l}33 \\
43 \\
48 \\
42 \\
42 \\
44 \\
44 \\
36 \\
38\end{array}$ & $\begin{array}{l}153 \\
213 \\
248 \\
261 \\
211 \\
204 \\
201 \\
199 \\
178\end{array}$ & $\begin{array}{l}364 \\
516 \\
657 \\
681 \\
548 \\
610 \\
675 \\
640 \\
626\end{array}$ & $\begin{array}{l}239 \\
343 \\
438 \\
455 \\
384 \\
460 \\
612 \\
707 \\
819\end{array}$ \\
\hline
\end{tabular}

Source: Annual Reports of the Registrar General, 1855 to 1962. * Less than 0.5 per year. 
year to this cause probably reflects the improvements in death registration which Farr was able to achieve; the effect of the Birth and Death Registration Act of 1874 , which imposed the duty of certifying the cause of death upon the medical practitioners in attendance; the marked progress of clinical medicine; and, perhaps, other factors. Abrupt increases in certain years suggest that changes in statistical practices may also have been responsible.

\section{$1881-1900$}

Death certificates were further improved in the 1880 s and 1890 s because of advances in medical education and medical practice, the simplified classification of diseases introduced by Ogle, stricter enforcement of the registration acts, and increased interest in vital statistics. Over 90 per cent. of deaths in the years 1881-1900 were certified by registered medical practitioners, 5 to 6 per cent. were certified upon a coroner's inquest, and less than 3 per cent. remained uncertified (Registrar General, 1907). A comparison of criticisms of death registration in the 1870 s (Maclagan, 1876) with criticisms voiced in the 1890s (Thompson, 1893) reflects clearly the considerable improvements which were achieved. Moreover, paralysis agitans was a well-recognized entity fully and extensively described in the medical literature of the latter part of the 19th century and was perhaps as familiar to the medical practitioner then as it is now.

The mortality data recorded by the Registrar General in the years 1881 to 1900 would thus seem to merit more serious attention than that for the earlier period, although by present standards it still possessed serious defects. The deaths certified upon a coroner's inquest were generally unsuitable for statistical treatment because the medical evidence of cause of death was often obscured by the wording of the verdicts returned by the laymen comprising the coroner's juries. In addition, the quality of certifications rendered by medical practitioners was sometimes unsatisfactory. In testifying to the Select Committee on Death Certification (House of Commons, 1893) Ogle observed that "the value of statistics based upon death certificates is somewhat impaired through want of uniformity in the terms employed ...", and he complained that "... much carelessness prevails amongst medical men in the matter of filling up the death certificate". It thus appears that an unknown but not insignificant number of deaths was either uncertified or inadequately certified. Thompson (1893), a proponent of reform, estimated that only 87 per cent. of the deaths registered in $\mathbf{1 8 9 0}$ were properly reported and classifiable.
The number of deaths ascribed each year to paralysis agitans continued to increase and nearly 5,000 deaths were assigned to this cause in the last two decades of the 19th century. Although it cannot be disproved that the disease may have increased in prevalence during the latter half of the 19th century, it seems more likely that the increased reporting reflected widening recognition of this entity among medical practitioners and improvements in death certification and statistical practices.

\section{Twentieth Century}

Before reviewing the mortality experience since 1921 , it is necessary to consider the effects of succeeding changes in the International Statistical Classification and the rules for coding. A major change occurred with the adoption of the Fifth Revision (1938) which took effect in 1940. In earlier years, from 1901-39, when more than one condition was entered on the death certificate, selection of the underlying cause to which the death was classified had been based on formal "rules for selection of one from two or more jointly stated causes of death" which had been used with only minor changes since 1901 (General Register Office, 1940). From 1940 onwards, the selection of cause of death has been "in the main that inferred from the statement of the certifier instead of being determined by arbitrary rules of $c$ reference" (Ibid., 1942). (The "joint-cause rules" were not suspended in the United States and other countries until 1949.) Thus, in the earlier period, priority was assigned to that condition which the deceased had experienced for the long time (giving preference to chronic conditions), while since 1940 , priority has been assigned to that condition which initiated the terminal episode.

The results of these changes in the rules for classification on the recording of paralysis agitans as the cause of death can be illustrated with two special analyses which have been summarized in Table II-A (opposite).

In 1925, paralysis agitans was classified as the underlying cause of death in 98 per cent. of the death certificates in which it was mentioned, and as a contributory cause in only 2 per cent. (Registrar General, 1947); in 1951 it was classified as a contributory cause in the majority of cases (Registrar General, 1954). The direct influence of the fifth and sixth revisions is shown in Table II-B (opposite). The 1,258 deaths assigned to this cause for the year 1939 under the new rules represent a 30 per cent. reduction from the 1,812 that were so assigned under the earlier rules (Table II-B). The effect of the Sixth Revision (1948) was much smaller.

In order to permit comparisons, the more recent data have been adjusted to reflect the presence of 
TABLE II

EFFECTS OF CHANGES IN SELECTION RULES AND IN THE CLASSIFICATION OF CAUSES OF DEATH

A. Changes in Selection of Underlying Cause of Death revealed by Multiple Cause Analysis

\begin{tabular}{|c|c|c|c|c|}
\hline \multirow{2}{*}{\multicolumn{3}{|c|}{ Classification of Paralysis Agitans }} & \multicolumn{2}{|c|}{ Year } \\
\hline & & & 1925 & $1951^{*}$ \\
\hline $\begin{array}{l}\text { Underlying Cause } \\
\text { Contributory Cause }\end{array}$ & $\begin{array}{l}\ldots \\
\ldots\end{array}$ & 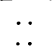 & $\begin{array}{r}1,025 \\
22\end{array}$ & $\begin{array}{r}73 \\
102\end{array}$ \\
\hline Total & $\begin{array}{l}\text { ber } \\
\text { ent. }\end{array}$ & & $\begin{array}{r}1,047 \\
97 \cdot 9\end{array}$ & $\begin{array}{r}175 \\
41 \cdot 7\end{array}$ \\
\hline
\end{tabular}

* Based on 10 per cent. sample for first 6 months.

B. Comparison of Mortality assigned to Paralysis Agitans under Fourth, Fifth, and Sixth Revisions of International Statistical

\begin{tabular}{|c|c|c|c|c|c|c|}
\hline Year & \multicolumn{3}{|c|}{1939} & \multicolumn{3}{|c|}{1949} \\
\hline \multirow[t]{2}{*}{ Revision } & 4th & \multicolumn{2}{|c|}{ Sth (1938) } & 5th & \multicolumn{2}{|c|}{ 6th (1948) } \\
\hline & No. & No. & $\begin{array}{c}\text { Per } \\
\text { cent. } \\
\text { Change }\end{array}$ & No. & No. & $\begin{array}{c}\text { Per } \\
\text { cent. } \\
\text { Change }\end{array}$ \\
\hline $\begin{array}{l}\text { Total .. } \\
\text { Men ... } \\
\text { Women }\end{array}$ & $\begin{array}{r}1,812 \\
926 \\
886\end{array}$ & $\begin{array}{r}1,258 \\
622 \\
636\end{array}$ & $\begin{array}{l}-30 \\
-33 \\
-28\end{array}$ & $\begin{array}{r}1,372 \\
588 \\
784\end{array}$ & $\begin{array}{r}1,417 \\
614 \\
803\end{array}$ & $\begin{array}{l}+3 \\
+4 \\
+3\end{array}$ \\
\hline
\end{tabular}

paralysis agitans at time of death. For this purpose the adjustments have been made separately for men and women for each of five age periods, using the comparative figures published by the General Register Office (1941, 1953).

Fig. 1 summarizes the prevalence of paralysis agitans at the time of death at various ages during the past 100 years. Referring first to the most recent experience, we can see that paralysis agitans is reported as present at time of death in only one individual 45 to 54 years of age among 100,000 persons alive at those ages; the rate is even lower below the age of 45 . There are four to six deaths with this diagnosis at ages 55 to $64 ; 24$ to 29 at ages 65 to 74 ; and 55 to 60 among 100,000 persons 75 or more years of age. This distribution is in keeping with the widely-accepted description of paralysis agitans as a disease of later life.

In tracing the mortality experience since 1855 , several distinct periods can be identified. Paralysis agitans was infrequently reported on death certificates before 1870 , but after 1875 the rate increased quite rapidly above age $\mathbf{7 5}$ and almost as rapidly for persons 65 to 74 years of age. Among younger

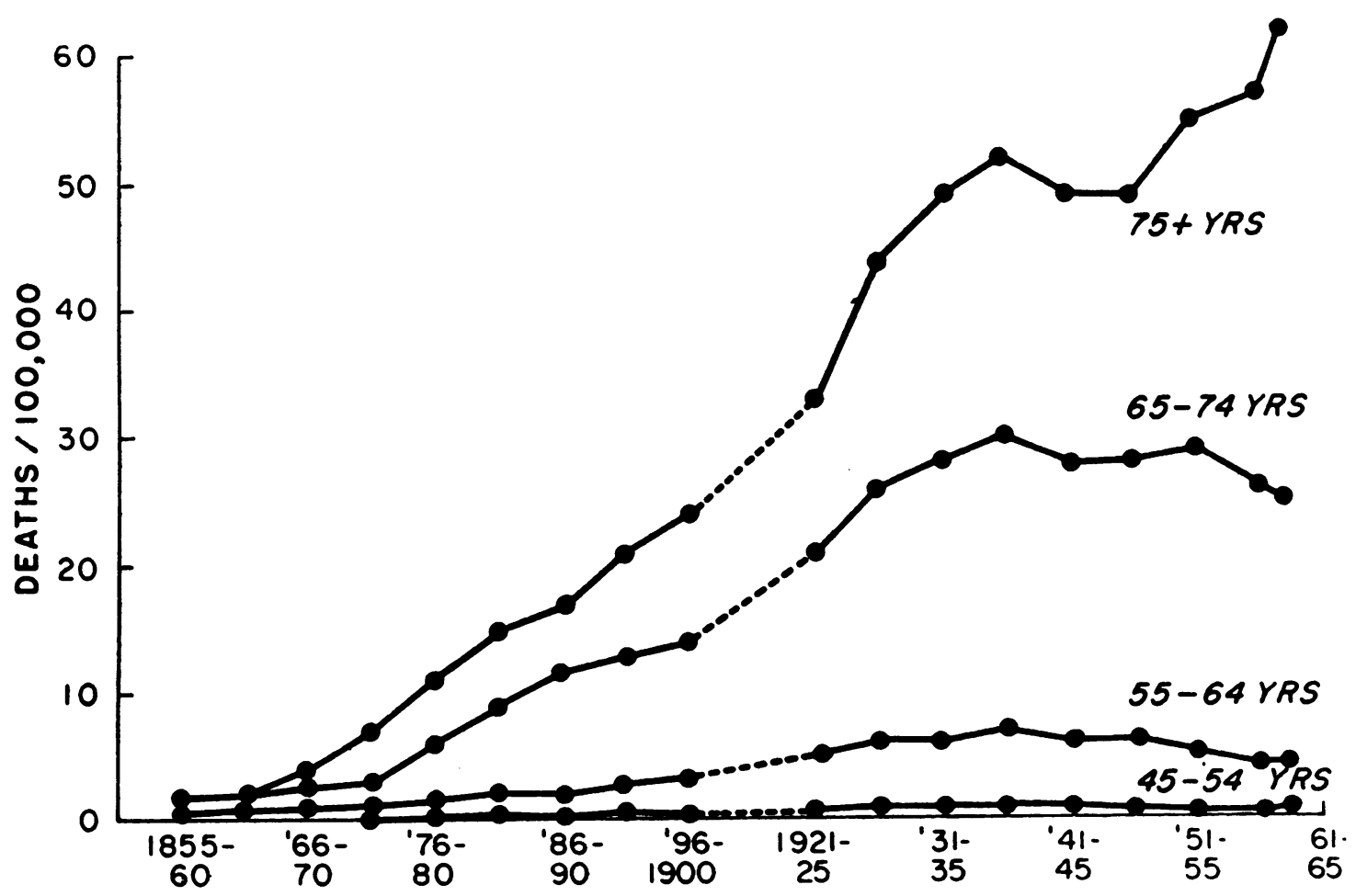

Fro. 1.-Age-specific mortality rates for paralysis agitans, 1855 to 1962. 
persons, however, the rate soon stabilized at low levels. By 1921-5, the frequency of paralysis agitans among deceased individuals was closely similar to that noted in recent years at all ages except the oldest. There is some indication of a small increase in paralysis agitans mortality at ages 65 to 74,75 years, and older, and possibly a slight increase in the younger age groups in the period 1926 to 1940 . The changes since 1921 are more clearly illustrated in Fig. 2, which shows the rates separately for men and women. It was during this period that the Parkinsonian sequelae of von Economo's encephalitis reached their greatest prominence. It is possible that some of these cases were incorrectly reported as paralysis agitans or, alternatively, that the wide interest in Parkinsonism generated in medical circles at this time led to increased recognition of paralysis agitans.
The age-specific rates for paralysis agitans levelled off about 1941 and there does not seem to have been any further increase except among persons over $\mathbf{7 5}$ years of age.

\section{Changes in Age at Death}

Ever since James Parkinson first described the "shaking palsy" in 1817 , it has been recognized as a disease of the later years. Fig. 3 (opposite) shows the trend in age composition from the time it was first listed separately in William Farr's reports. The younger cases, under age 55 , never formed a large percentage of paralysis agitans deaths and in recent years have fallen to about 3 per cent. of the total number. There has been a large decline in the proportion of paralysis agitans deaths in the age range 55 to 64 . In the mid-19th century, deaths in these ages accounted for 20 to 24 per cent. of the total for all

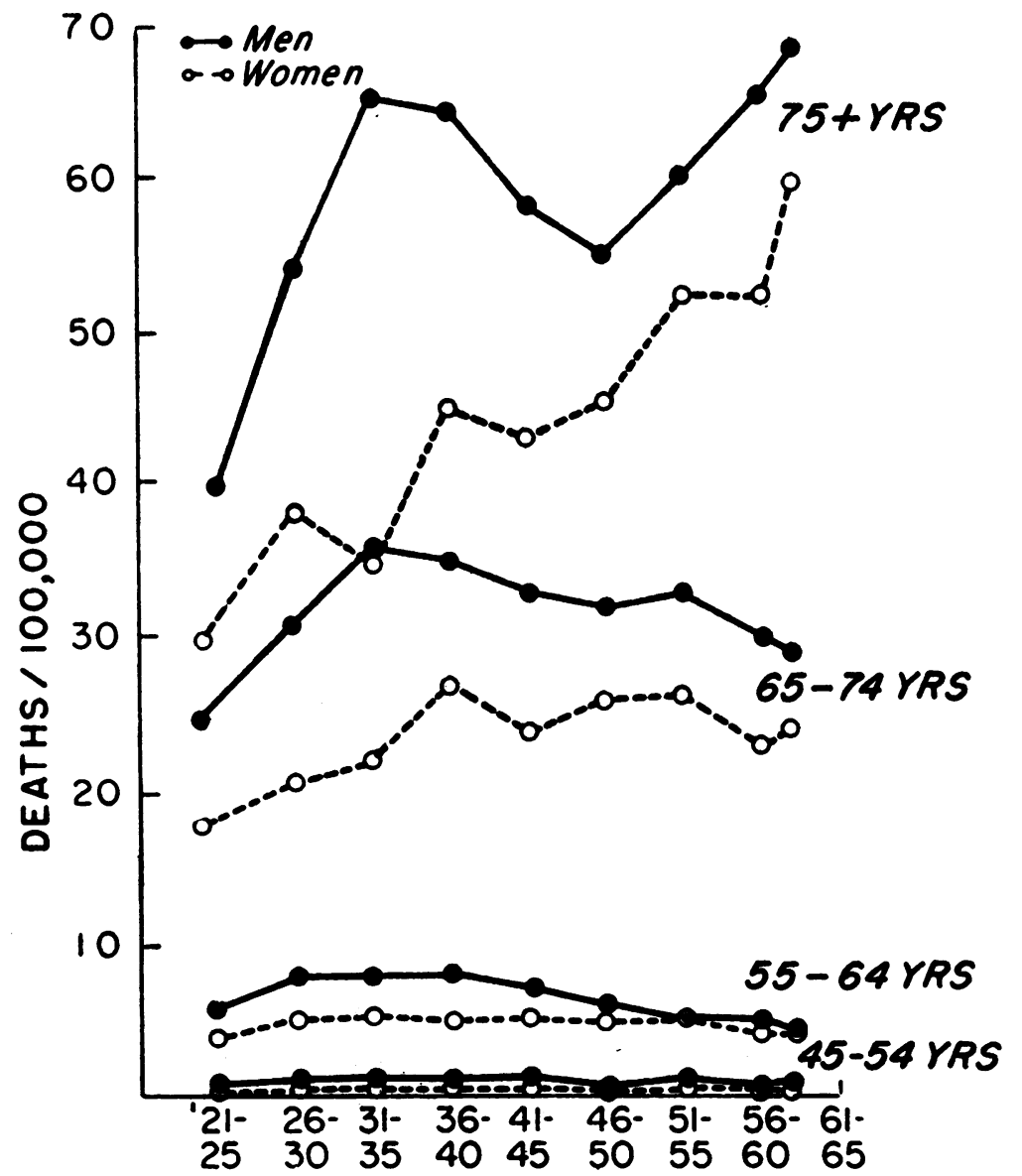

F10. 2.-Comparison of apo-specific mortality rates for paralysis agitans in men and women, 1921 to 1962. 


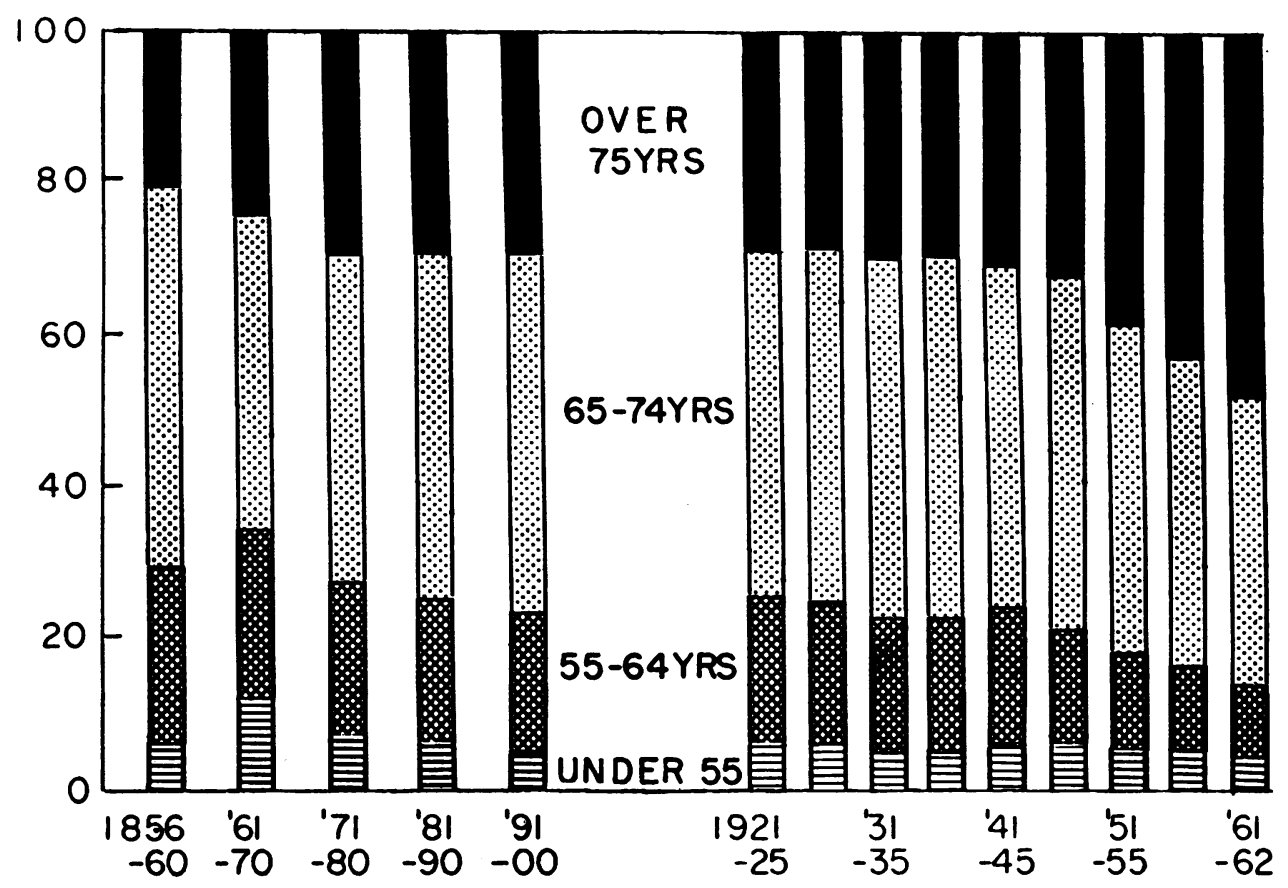

FIG. 3.-Changes in age distribution of paralysis agitans mortality over the past century.

ages. In the 100 years that have elapsed the proportion has been halved, accounting in 1961-2 for only 10 per cent. For the age group 65 to 74 years, there has been little change; these accounted for 41 per cent. of the paralysis agitans deaths in the 1860 s and the same percentage in recent years. Perhaps the most notable change has occurred among the elderly. Deaths over age 75 , which accounted for only 25 per cent. of the total before 1900 , have been charged with over 40 per cent. since 1956.

Why is the mortality rate increasing for persons over 75 years of age while remaining stationary at all other ages? Several possible interpretations are suggested. The increase may reflect a greater willingness of physicians to invoke this diagnosis among the elderly in cases that formerly might have been considered as "within normal limits". If this is so, it may be a correction of previous underreporting in this age group. On the other hand it may represent a tendency toward over-diagnosis. It is also possible that the increase is not due to differences in diagnosis or in reporting but that it may represent a continuation of factors which have been steadily increasing the risk of paralysis agitans among the elderly for 50 years or even longer. The data presently available do not permit a choice among these hypotheses.
SeX DifFerences

In the years 1855 to 1870 deaths among men outnumbered those among women by $3: 2$, while more recently the ratio has been reversed. Deaths among women now exceed those among men, particularly over the age of 75 . In 1962, there were 963 deaths in women compared to 697 in men (ratio 4:3). Agespecific mortality rates for both sexes since 1921 are shown in Fig. 2. The mortality rates have been consistently higher in men than in women. Since 1951 the annual rates have been 60 to 68 per 100,000 men aged 75 years and above compared with 52 to 59 among women of the same ages. For ages 65 to 74, the rates have been 29 to 33 per cent. for men and 23 to 26 per cent. for women; for younger ages the annual rate is below 5 per 100,000 in both sexes. Fig. 4 (overleaf) shows the extent to which the differences between the sexes have narrowed in recent years. Below age 65 they have all but disappeared; even in older persons the excess mortality among men in recent years is about half what it was 30 years ago.

The tabulations of multiple causes of death from which Table II-A has been derived provide some information on associated causes of death among cases in which paralysis agitans was named as the underlying cause. The most frequently mentioned were cardiovascular disease, vascular disease of the 


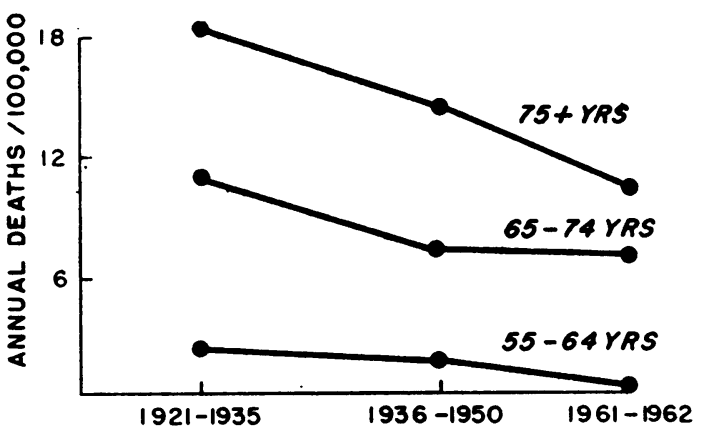

FIG. 4.-Excess mortality assigned to paralysis agitans in men as compared with women, 1921 to 1962.

central nervous system, pneumonia, and bronchitis. The association with heart disease seems commensurate with the age range affected. The frequent occurrence of bronchopulmonary disease is not surprising in elderly invalids. There appears to be a low association with malignant disease. There is no striking association with diabetes mellitus or cerebrovascular disease as might be anticipated if arteriosclerosis were a major aetiological factor.

\section{COMMENT}

The constancy of paralysis agitans mortality over the past $\mathbf{4 0}$ years is remarkable. Making allowances for changes in medical and statistical practices, we are tempted to conclude that the risk of dying with paralysis agitans is about the same to-day as it was in the 1920s and that it has not in fact changed since the $1890 \mathrm{~s}$. Whatever influence the epidemic of encephalitis lethargica may have had, no long-term residual effect is apparent. Nor have the profound environmental changes of the past half-century appeared to exert any influence upward or downward.

The age-specific death rates and the age distribution of deaths (Figs 1, 2, and 3) both show an increase in the proportion of cases among the elderly. The largest increase is in persons aged $\mathbf{7 5}$ years and above. This group now accounts for approximately half of the deaths in persons with paralysis agitans, more than double the proportion noted a century ago. Possibly these increases reflect changes in medical practices. Greater attention to the signs and symptoms of the aged has reduced the use in death certificates of vague and non-specific terms such as senility and debility. This may not be the entire explanation, however, since the age at onset has increased only modestly during the past century (Duvoisin, Yahr, Schweitzer, and Merritt, 1963).

It is commonly stated that paralysis agitans occurs more frequently in men than in women and most published clinical series include a preponderance of men.

There was, however, no sex difference in the prevalence of paralysis agitans in Logan's study of National Health Service patients, but men with the disease sought medical attention more frequently than women (Logan and Cushion, 1958). In view of the excess mortality due to paralysis agitans in men in the earlier age groups one may wonder whether the disease is more severe in men though not more common. If so, one might anticipate that in the age range above 75 years the diagnosis will be made more frequently in women. No data are available on this point.

Progress in medical science, including vital statistics, inevitably brings changes in classification and tabulation. One troublesome point has been the definition of primary and secondary causes of death. Recent practice has emphasized the events surrounding the terminal episode. This has had the unfortunate effect of obscuring the role of many chronic afflictions; diabetes and primary hypertension are good examples. We have noted that paralysis agitans was reported more frequently under the old rules which specified that causes of death should be noted "in the order of their appearance, and not in the presumed order of their significance" (General Register Office, 1845). It has only been possible to make the long-term comparisons included in this paper because of the foresightedness? of the Registrar General in providing tabulations by the old as well as the new rules whenever changes were put into effect. We were thus able to adjust our tabulations for recent years to reflect all the cases in which paralysis agitans was noted to be present at the time of death; or in other words, to estimate the number of cases dying with the disease, not alone those for which it was considered to be the immediate cause of death.

The present analysis of paralysis agitans mortality illustrates the usefulness as well as the limitations of mortality statistics. When other clues to aetiology are lacking, as is often the case in chronic diseases, variations in occurrence or severity in time or place may indicate which among several possible areas of investigation are more likely to be fruitful. Thus, the unexpected finding of the present investigation that the great social and environmental changes of the 20th century have not appreciably modified the reported prevalence at time of death suggests that the study of familial and constitutional factors may hold promising clues to aetiology.

Although a beginning has been made in the investigation of geographical and national differences (Goldberg and Kurland, 1962), the data from various countries must be subjected to the 
same type of analysis as that which we have attempted for the data from England and Wales. Publication of extensive multiple-cause tabulations from death certificates would provide further insight into the course and outcome of paralysis agitans and its interrelations with other diseases. Consideration should also be given to the possibility of incorporatting in the death certificate a statement of chronic disease diagnosis whether or not it is presumed to be of significance in the terminal process.

\section{SUMmaRY}

(1) The annual reports of the General Register Office for England and Wales provide mortality data for paralysis agitans dating back to 1855 . Starting from a handful of cases in the early years, and increasing rapidly after 1875 , reported cases have recently tended to level out at fewer than 2,000 cases per year.

(2) Annual mortality rates in recent years have been 55 to 60 per 100,000 persons over 75 years of age, and 25 to 30 for age 65 to 74 years. At younger ages, the rates are much smaller.

(3) Although the cases among men exceeded those among women in the earlier years in a ratio of $3: 2$, current experience shows an excess of women. This is due to the greater proportion of women surviving to old age. Age-specific rates continue higher in men than women at all ages although the differences have become very small in recent years.

(4) Mortality rates have been stationary for the past 40 years or more at most ages. Only in persons aged 75 years and above is there evidence of a continuing rise.

(5) Although no significant associations of paralysis agitans mortality with other diseases could be demonstrated, there is need for more extensive tabulations of the multiple causes which physicians commonly include on death certificates.

\section{REFERENCES}

Charcot, J. M. (1880). "Leçons sur les maladies du système nerveux", 3rd ed. Delahaye, Paris.

Duvoisin, R. C., Yahr, M. D., Schweitzer, M. D., and Merritt, H. H. (1963). Arch. Neurol. (Chicago), 9, 232.

General Register Office (1845). "Registration of the Causes of Death", 2nd ed. HMSO, London.

_ (1940). "Manual of The International List of Causes of Death". Based on The 5th Decennial Revision by The International Commission, Paris, 1938.

Goldberg, I. D., and Kurland, L. T. (1962). Wld Neurol., $3,444$.

Logan, W. P. D., and Cushion, A. A. (1958). "Morbidity Statistics from General Practice, Vol. 1 (General)". General Register Office-Studies on Medical and Population Subjects, No. 14, HMSO, London.

Maclagan, J. M. (1876). Sanit. Rec., 5, 65.

Parkinson, J. (1817). "An Essay on the Shaking Palsy". Whittingham and Rowland, London.

Registrar-General (1855-1962), "Annual Reports". London.

(1907). "Decennial Supplement to the 64th Annual Report".

(1947). "Decennial Supplement England and Wales 1931. Part IV: Multiple or Secondary Causes of Death". HMSO, London. page 250 (1954). "Statistical Review for 1951", Part III,

Sanders, W. R. (1879). In "A System of Medicine". 2nd ed., J. R. Reynolds. Philadelphia.

Thompson, H. (1893). Brit. med. J., 1, 57. 